to the Board by householders and physicians. That Board has publicly offered to superintend the process of disinfection, if requested to do so by the householder. Dr. Kellogg thought it desirable that Boards of Health superintend disinfection after contagious diseases, where possible. He thought disinfection by sulphur would be more efficacious, if carried on in a moist atmosphere.

Drs. Hazlewood and Baker were appointed a committee to examine and report on text-books on hygiene with special reference to alcohol, if any such books are sent to the Board for examination.

Dr. Kellogg for himself and Dr. Avery, Special Committee on the Present Knowledge Respecting Diphtheria, reported a paper embodying a large number of replies to a circular of inquiry, some being very valuable. The report was accepted with thanks, and ordered printed in the annual report.

The next meeting of the Board will probably be for the examination of plans for buildings at the State Reform School.

\section{DOMESTIC CORRESPONDENCE.}

Cameridge, Mass., Oct. 29, I 883.

\section{N. S. Davis, M.D., Editor:}

In an able and comprehensive report of the committeee on Practical Medicine and Epidemics of the Illinois State Medical Society, for I882-3, published in the weekly Journal of THE AMERICAN MEdical Association, October I3, last, the virtues attributed to alcohol as an internal remedy for its germicide power is referred to ; also in the same report is mentioned Dr. G. M. Sternberg's recent experiments on the germicide powers of a large number of medicinal agents. According to this report Dr. Sternberg's experiments show that the micrococcus of pus one of the most easily destroyed germs required the presence of 20 per cent. of alcohol for its destruction, while the bacteria termo survived after being immersed in a solution of 95 per cent. alcohol twenty-four hours. From this it is calculated that the amount of alcohol required to be present in the blond of a patient weighing $\mathbf{I} 60$ pounds, to destroy the germs most susceptible to its influence would be more than a quart, "a much larger quantity than the most enthusiastic advocate of its use would deem safe to administer." Considering the importance of the subject, and having been accustomed for a long time to believe that many diseases and pathological conditions are dependent upon the presence of the germs, and that the administration of full but safe doses of alcoholic liquors when resorted to early, have been productive of much benefit in aborting or cutting short septic and zymotic diseases, I have thought it worth while to dwell somewhat upon the subject and to see whether there can be discovered certain factors or conditions which tend to substantiate such clinical experience. I believe too, there is a growing feeling and experience on the part of the medical profession that there are many medicinal agents which can be administered in doses practically safe for the patient, and yet be sufficiently effective for the destruction of the supposed germs or at least so as to modify its habits and constitution in its pathogenic condition, that its ravages on the human organism can be arrested or prevented.

In referring to the careful and elaborate experiments of Dr. Sternberg, it appears they, for the most part, were conducted in culture apparatus outside of the body and thus his experiments only represent the results of the germicide reagents or germs other than pathogenic ones, a distinction very important to be kept in mind by the experimenter if he expects much value to result from his labors. For instance, if a certain amount of alcohol or other reagent is required to destroy or modify a micrococcus in a culture fluid outside of the animal organism, who will venture to say that that amount of the medicinal agent is needed after the micrococcus has gained admission into the blood, which in the early stages of disease may be well-nigh fatal to such micrococcus? Sternberg has recognized this distinction and has more than once made mention of pathogenic organisms. Sternberg remarks in one place as follows: "Evidently therapeutic value, assuming the correctness of the germ theory, cannot be gauged by germicide power alone, for it is possible that a reagent, which possesses this power in but slight degree or not at all may nevertheless be capable of restricting the development of pathogenic organisms, and thus limiting their power for mischief." "Now, if it be permissible to take this view in the premises, as Sternlerg has sanctioned, should we not look upon his own "Experimental data," as helps only in a most general way in our therapeutic practice? Surely with such a view of the case it would not seem to be necessary to give a quart of 95 per cent. alcohol, nor three and one-half grains of mercuric bichloride to prevent the development of the septic micrococcus in the blood.

Sternberg, speaking of "Bacteria in healthy individuals," says Nature has placed, or in other words, evolution has developed in the living tissue of animals, a resisting power aganst the encroachments of bacterial organisms invading and surrounding them, which is sufficient for ordinary emergencies. But when the vital resistance of the tissues is reduced, on the one hand by wasting sickness, profuse discharges, etc., or on the other the vital activity of the invading parasitic organism is increased, the balance of power rests with the infinitesimal but potent micrococcus." Again he says: "Certainly there would be an end to all animal life, or rather there never would have been a beginning, if living animals had no greater resisting power to the attacks of these parasites, which by numbers and rapid development make up for their minute siz:, than has dead animal matter."

These two citations not only bear the impress but the seal of philosophic and demonstrated truth, and this will all the more appear self-evident when we consider the fact that the micro-organism is isolated from the living animal and placed in a culture fluid when he has rio enemies to encounter nor obstacles to overcome, but on the other hand has the best possible chance for full and perfect development out of the rich and highly nourishing pabulum offered for 
nis choice. Under such circumstances is it any wonder he becomes, if not a formidable, at least an extremely tough beast? Such being the fact our therapeutic practice, notwithstanding the many experiments claimed to have been so elaborate and painstaking, must, as already intimated, depend almost entirely upon eimpiricism, clinical experience and observation in the choice and use of medicinal agents of supposed germicide nature. This thought further leads to the consideration that the product of these giant or monster germs on entering the animal tissues may take on a retrograde process, or as it were, a sort of atovistic condition in which they may become sensitive to exceedingly small doses of germicide reagents. However this may be, all that is necessary for the therapeutist is, so to apply his medicinal agents that the development of the pathogenic micro-organism shall be arrested, if not by being destroyed, by being rendered hors-du-combat until the vital powers of the animal organism can react and the intruding micrococcus be expelled from its borders. Very respectfully,

Augustus P. Clarke, M.D.,

693 Main St., cor. Bigelow St.

\section{BOOK REVIEWS.}

Transactions of the Medical Society of the State of Pennsyinania. Thirty-fourth annual session. Volume XV., I883. Published by the Society.

The most casual observer of medical progress in the United States must have noticed from the report of the proceedings annually made in the medical journals that the Medical Society of the State of Pennsylvania is accomplishing a great deal of valuable scientific work. For several years the annual volume of transactions has been found teeming with records of experimental and clinical investigation, giving the results of the labors of the most eminent and accomplished physicians of Philadelphia and the entire State of Pennsylvania. Such original observers and indefatigable workers as Oscar H. Allis, R. J. Levis, William Goodell, Trail Green, R. S. Sutton, Wm. Pepper and James C. Wilson have chosen the annual meeting of the State Society as the occasion for presenting to the profession the result of their work. The volume before us embodies the proceedings of the thirty-fourth annual session, held at Norristown in May, 1883 .

The address of the President, Dr. William Varian, of Titusville, is devoted to the consideration of some interesting hygienic problems, among others we note the question of cremation and modern means for the restoration of inebriates. The address throughout is thoughtful and suggestive.

The address on Medicine is by Dr. James Tyson of Philadelphia, and is a brief paper on "Malarial Hæmaturia." We presume its published title is adopted solely to comply with custom, since no report is made of recent advances in medicine or any of the topics usually discussed under this title of the "Address in Medicine in Medical Societies." This paper occupies only seven pages, is carelessly written, and contains nothing strikingly novel or unique. We believe Dr. Tyson could have prepared a paper more worthy the occasion. The "Address in Surgery," is by Dr. Alex. Craig, of Columbus; the "Address in Obstetrics," a most interesting paper, is by Dr. George $O$. Moody, of Titusville; the "Address in Hygiene," is by Dr. Henry Leffmann, of Philadelphia; and the "Address in Mental Disorders," is by Dr. John Curwen, of Warren ; Dr. Peter D. Keyser, of Philadelphia, contributes "Some Ophthalmological Observations During Ten Years Service in Mill's Eye Hospital," illustrated by numerous wood cuts, which will interest the cultivators of ophthalmic science. Dr. Lowry Sibbett, of Carlisle, relates his experience in obstetric practice, with an analysis of one hundred consecutive cases. Dr. Hugh Hamilton, of Harrisburg, contributes an article on "Artificial Infant Alimentation," which is the result of extensive investigation and study. The subjact is treated from the stand point of chemical analysis and physiological action, and does not include a clinical study of the various articles for artificial infant feeding. This subject is of such vital importance and demands such increasing consideration with our growing civilization, that every contribution to the subject is welcome. This volume contains two papers on "Insane Asylums and the Management of the Insane." We heartily wish that every official of all the insane asylums of this country would read and ponder that of Dr. Samuel Ayers, of Pittsburg, entitled "Our Asylums and our Insane." The other paper treats of "Insane Asylums and their Relations to the Community," by Dr. R. H. Chase, of Norristown. Dr. DeForest Willard, of Philadelphia, in an admirable article advocates the "Early Treatment of Club Foot," deprecating the custom which "waits for the child to be old enough for the operation." Dr. E. A. Wood, of Pittsburg, treats of "Deformity Following Dislocation of the Foot Outwards at the Ankle Joint."

Dr. Samuel W. Gross, of Philadelphia, presents in brief a Plea for the Early and Thorough Removal of Carcinoma of the Breast. His views on this subject have been made current through his Treatise on Mammary Tumors and in several papers published in the last few years.

Dr. James C. Wilson, of Philadelphia, in a scholarly paper presents the Modern Method of Treating Purulent Pleural Effusions. Dr. Wilson demonstrates his well-known ability as an accomplished and expert clinician in this article. It is in reading such a paper as this that we regret that the Transactions of Societies are not more widely distributed. Dr. Wilson's paper is so thoroughly practical and treats of such an important class of cases that it should be in the hands of every practitioner in the land. The treatment is based upon the principle that the containing pus cavity is to be emptied and then obliterated by reparative inflammation. For this purpose it is deemed essential that the opening when made into the chest be kept open, drained by a retained tube, and washed out daily. We give Dr. Wilson's method in so far as descriptive of the oper- 